\title{
Use of MTA in Conjunction with an Intraradicular Endodontic File Splint for Treatment of Horizontal Root Fracture: A Case Report
}

\author{
Bhagwat Sumita A.*, Gundre Priyanka P and Padhye Leena V. \\ Dept. of Conservative Dentistry \& Endodontics, DYPU College of Dentistry, Nerul, Navi Mumbai, India.
}

\section{ABSTRACT}

With the possibility of harnessing the regenerative potential of tissues, clinicians will find greater clinical instances where an old treatment modality used in conjunction with new materials gives greater clinical success in cases with poor clinical prognosis.

This case typically illustrates such a situation where we successfully used МТАтм in conjunction with an endodontic file used as an intracanal splint for repair of horizontally fractured root with minimal displacement of the fragments.

\section{Keywords: MTA, Endodontic File, Horizontal Root Fracture}

\section{Introduction}

Trauma followed by fracture and mobility of a tooth creates great distress for a patient. In such a situation, a patient appreciates all efforts made by the treating dental professional to retain the natural tooth. Presence of fracture fragments precludes any routine procedures for preservation of the tooth. But it has been noted that if the displacement between the fragments in minimal, intracanal stabilization can improve the prognosis of the treatment. ${ }^{1}$

\section{Case report}

A 21 year old male patient reported to the Dept of Conservative Dentistry \& Endodontics at DYP University School of Dentistry with a chief complaint of loose tooth in the upper anterior region. History revealed trauma to upper anterior teeth around one and a half months earlier while working at a road construction site. Patient also gave history of incomplete treatment with the adjacent tooth. Medical history was not contributory.

On examination, Grade 1 mobility was observed with 11, and it was non-tender to percussion. The electric pulp vitality test showed it to be non-vital. No signs of trauma or mobility were detected with 21 and there was no tenderness on percussion.

On radiographic examination, a horizontal fracture was detected in the middle third of the root of 11, separating the coronal and apical root fragments from each other by about $1 \mathrm{~mm}$. There was no significant bone loss. The two fragments were slightly misaligned (less than $1 \mathrm{~mm}$ ). 21 showed the appearance of being incompletely treated. Fig 1 shows the clinical presentation of the patient and the radiograph at the time of initial presentation.
Root canal treatment with tooth 11 with intraradicular splint and MTA was planned. The treatment was explained to the patient and written consent was obtained. Approval and clearance was obtained from the Institutional Ethical Committee and all protocols and procedures were in accordance with the standards of the Helsinki Declaration.

After rubber dam application, access opening was achieved under local anesthesia and working length was estimated with a size $10 \mathrm{k}$ file (Fig 2- left). The $10 \mathrm{k}$ file was precurved so as to engage both the fragments of the fractured root. Pulp tissue was extirpated and the canal was irrigated with saline. An intracanal $\mathrm{Ca}(\mathrm{OH})_{2}$ dressing was given and cavity was sealed with temporary cement. During next appointment, cleaning and shaping of the canal was done by conventional method using $2 \%$ taper instruments. A master cone of size 45 was selected and the apical fit of the cone was confirmed (Fig 2-right).

Apical sectional obturation of $4 \mathrm{~mm}$ was carried out with the selected master cone to seal the apex (Fig 3-left). Then a new and autoclaved $40 \mathrm{k}$ file was selected as intra-radicular splint. It was cut to fit in the canal and loosely engage both fragments of the root (Fig 3-right).

During the next appointment, the canal was filled with $\mathrm{MTA}^{\mathrm{TM}}$ and then the selected and sterilized file was coated with $\mathrm{MTA}^{\mathrm{TM}}$ and inserted into the canal to act as intracanal splint (Fig 4-left) Post endodontic restoration was carried out with GIC base to seal the orifice and composite resin restoration (Fig 4-right). A fiber post was placed in 21 and post endodontic restoration was carried out with GIC base and composite resin restoration. A ceramic crown was fabricated and cemented for 21 later. 


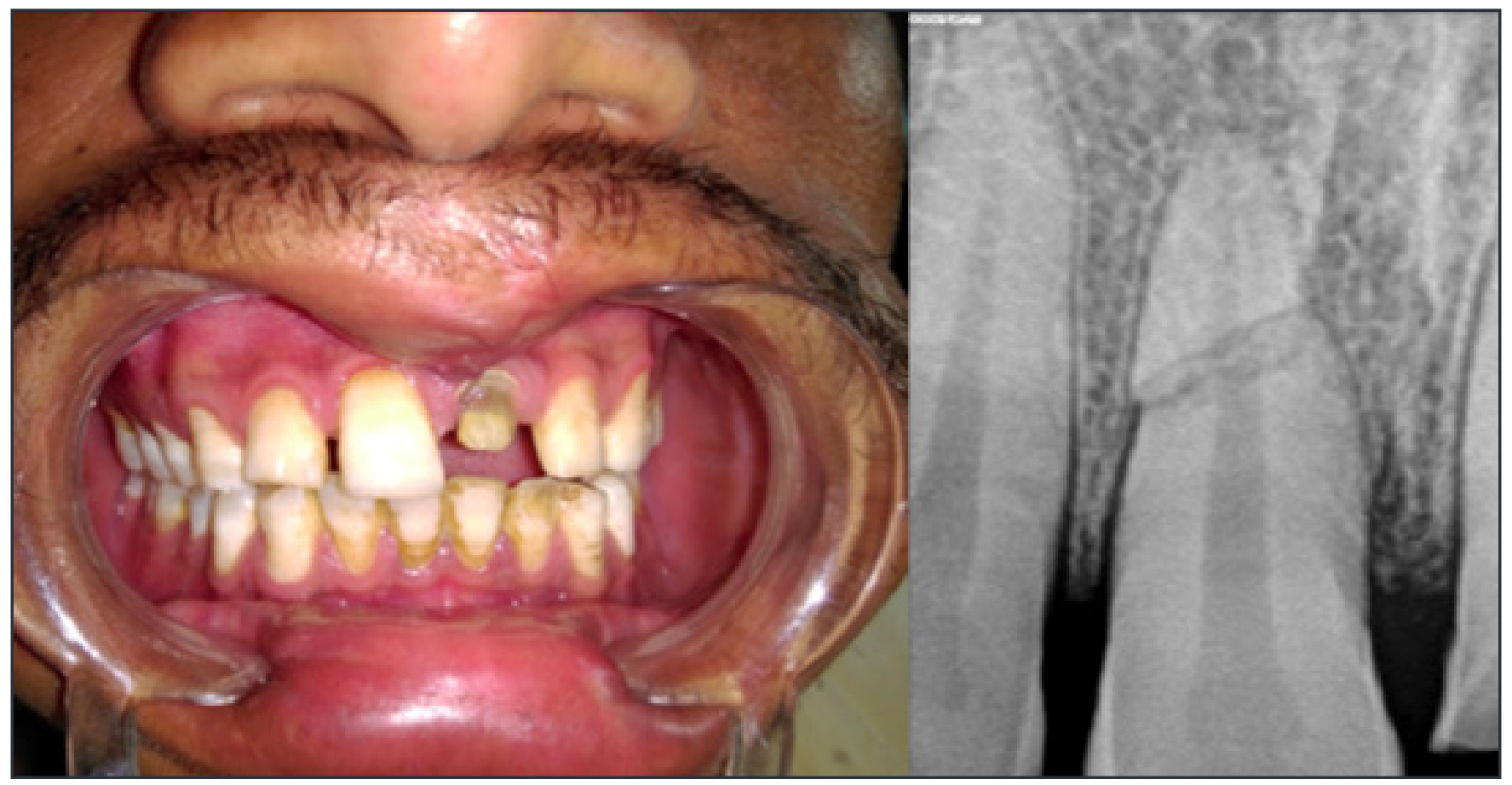

Fig. 1: Left: Initial clinical presentation \& Right: Radiograph at the time of initial presentation.

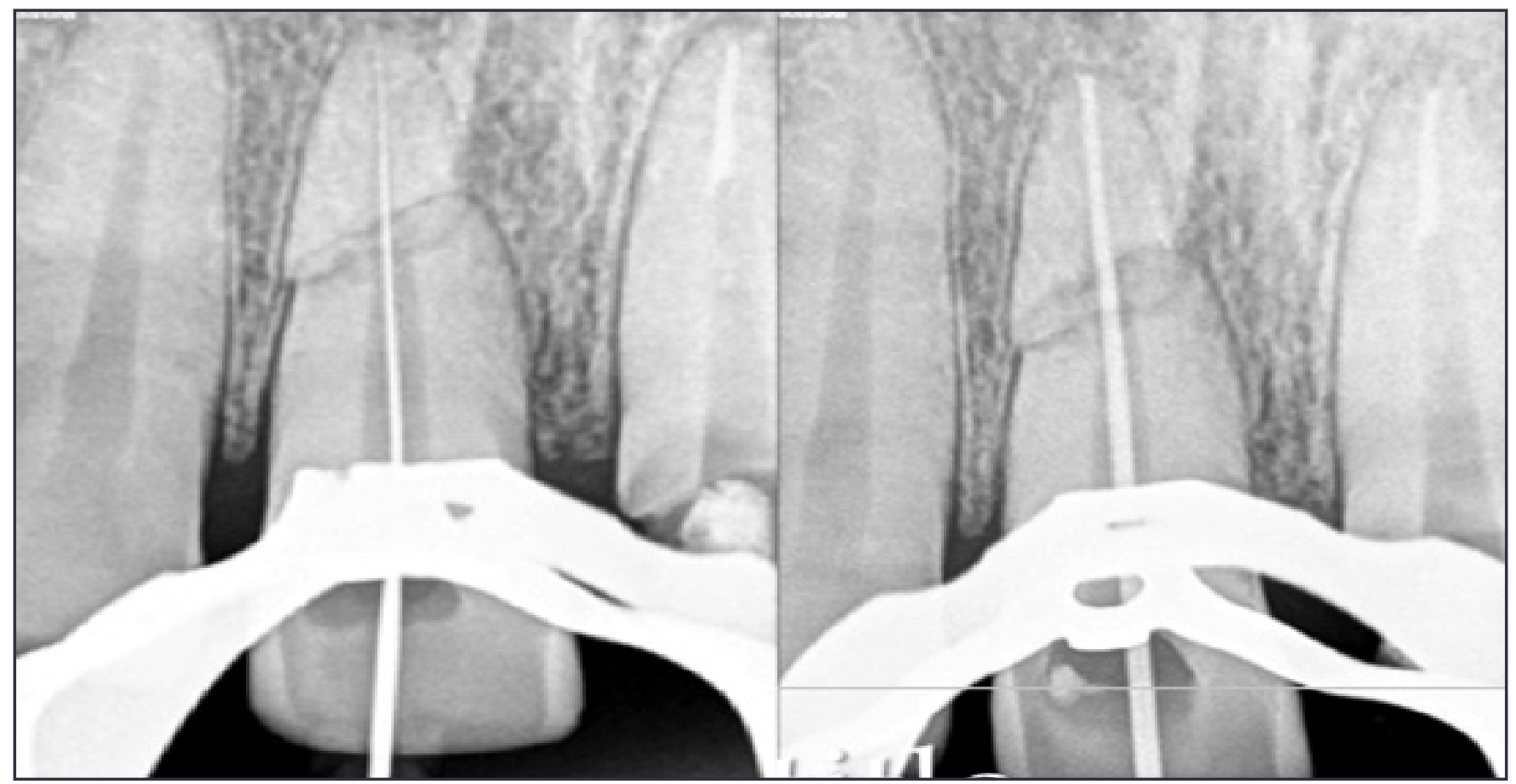

Fig. 2: Left: Working length determination; \& Right: Mastercone selection.

Annals of Oral Health and Dental Research, Vol. 1; Issue 1, October-December 2017 


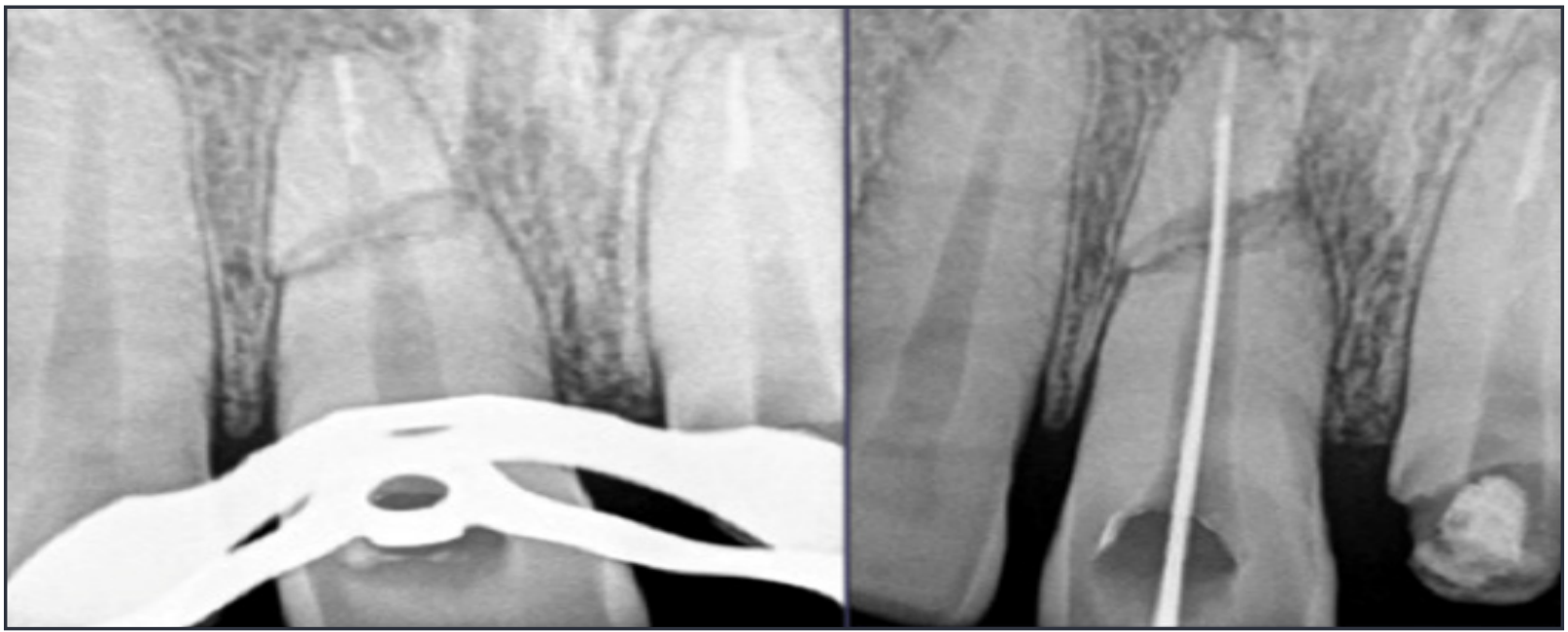

Fig. 3: Left: Apical sectional obturation; \& Right: Selection of $40 \mathrm{~K}$ file for splinting.

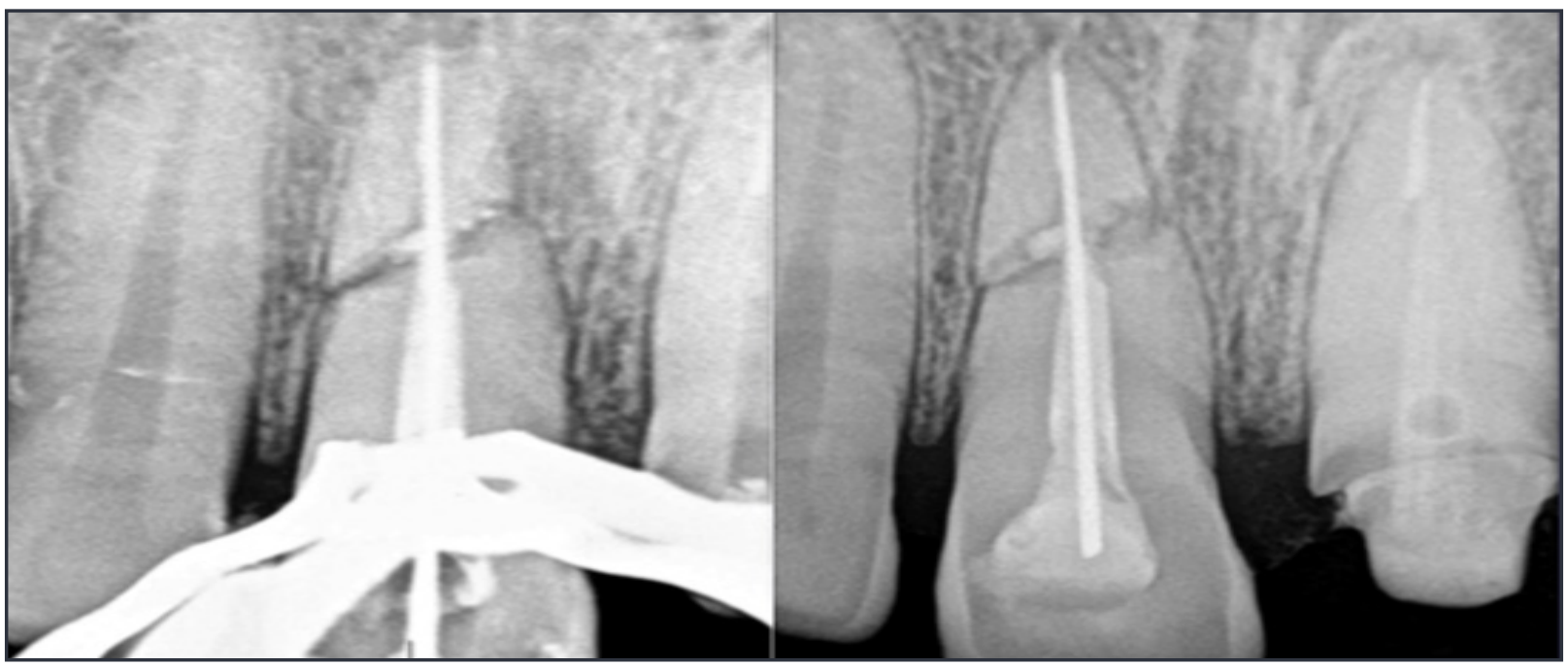

Fig. 4: Left: Cementation of the splint into the canal with MTA; \& Right: Post-endodontic restoration with 11 and 21

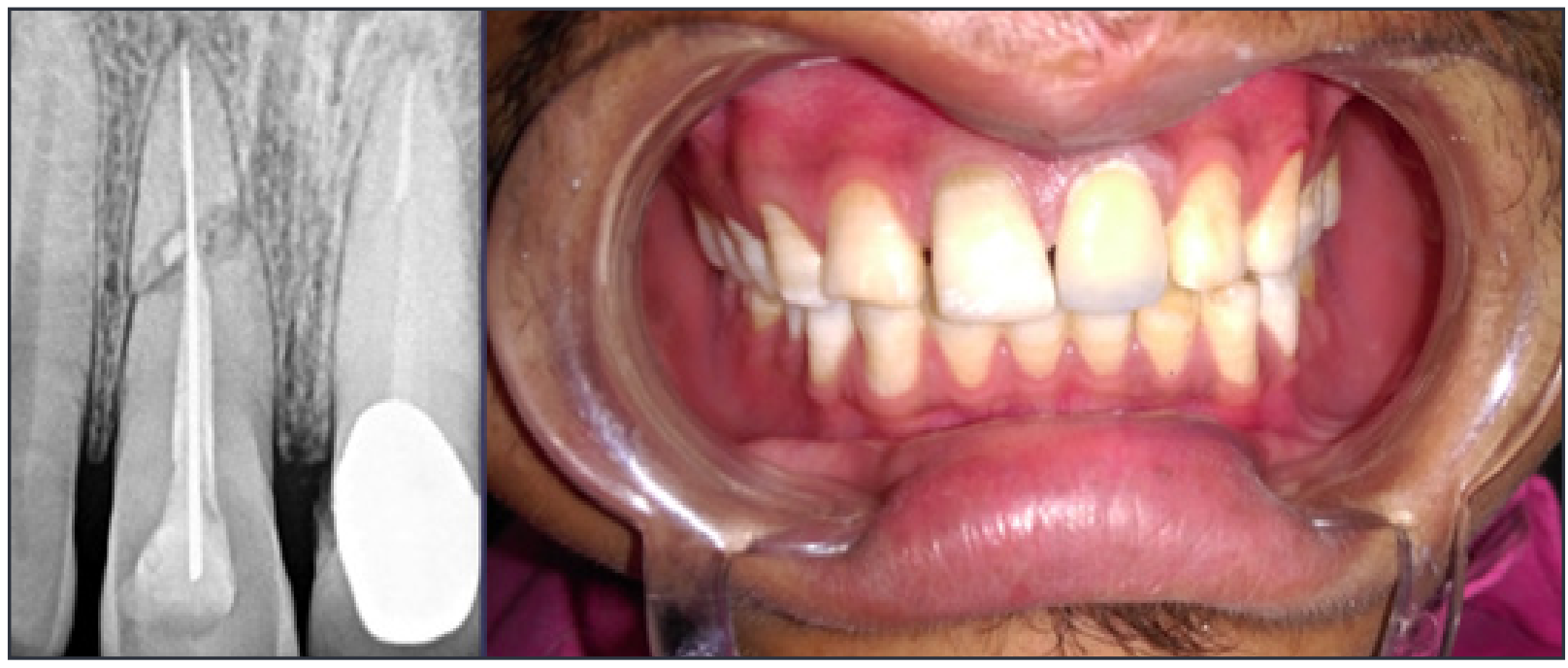

Fig. 5: Left: Radiograph at 6-month follow-up; \& Right: Clinical picture at 6 month follow-up. 
On 6-month recall, the patient was comfortable with no complaints with the treated tooth. Pain on percussion was negative and no mobility was detected. A radiograph at the 3-month follow up (Fig 5) showed hard tissue formation between the two fragments of the fractured tooth. The radiolucent fracture line (that was visible in the preoperative radiograph) was not discernible and there was no other radiolucency indicative of any kind of resorptive activity.

\section{Discussion}

Splints are used to limit tooth movement, prevent the drifting of teeth, and protect the teeth from secondary tauma due to occlusion. Glickman defines a splint as being an appliance utilized in the stabilization of injured parts. When teeth are excessively loosened by acute trauma or periodontal disturbances, stabilization by splinting can

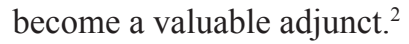

Endodontic implants were introduced in the1960s. Endodontic implants are artificial metallic extension, which can safely extend out through the apex of the tooth into sound bone.They aimed to increase the root to the crown ratio and stabilize a tooth with weakened support. Endodontic implants enjoyed few successes and many failures. Various reasons for failures included improper case selection, improper use of materials and sealers and poor preparation for implants. ${ }^{3}$ Due to these reasons, endodontic implants have lost favour as a treatment moality in the last 4 decades.

In the present case, the crown showed no mobility and the 2 fragments were minimally displaced. Hence, the perceived requirment was for some kind of stabilization which would engage both fragments. A screw post was not advisable as the threads would exert pressure on the fragments and an orthodontic wire would not be of sufficient width and strength required for stabilization ${ }^{4}$. Hence, we chose to use a sterile unused $\mathrm{k}$ file of size 40 as an intracanal stabilizer. Literature search for intracanal stabilization shows many cases of horizontal fracture of the root with intracanal stabilization with endodontic files ${ }^{1}$, but the same technique used in conjunction with MTA has been sparsely studied ${ }^{5}$.

Cementation of an intracanal stabilizer has been traditionally carried out with GIC or Polycarboxylate cement in the past ${ }^{6}$. With the availability of $\mathrm{MTA}^{\mathrm{TM}}$, it is possible to try to induce regenerative tissue formation at the fracture line by using it. MTA has been widely used in the recent years for pulp capping, partial pulpotomy, perforation repair, resorption repair, repair of fracture , , root end filling, apical barrier for tooth with necrotic pulp and open apex, coronal barrier for regenerative endodontics , root canal sealer. ${ }^{7}$ Investigations have proved successful when MTA has been used in in vitro studies as a retrograde filling material as well. ${ }^{8}$

\section{Conclusion}

With the possibility of harnessing the regenerative potential of tissues, clinicians will find more and more clinical instances where an old treatment modality used in conjunction with new materials gives greater clinical success in cases with poor clinical prognosis.

This case illustrates one more clinical presentation where $\mathrm{MTA}^{\mathrm{TM}}$ may be successfully employed for repair of fractured root fragments with minimal displacement.

\section{References}

1. Kocak S, Cinar S, Kocak MM, Kayaoglu G. Intraradicular splinting with endodontic instrument of horizontal root fracture--case report. Dent Traumatol. 2008 Oct;24(5):578-80.

2. Perlitsh MJ. A systematic approach to the interpretation of tooth mobility and its clinical implications. Dent Clin North Am. 1980 Apr;24(2):177-93

3. Rakesh K. Yadav, A. P. Tikku, Anil Chandra, K. K. Wadhwani, Ashutosh kr, and Mayank Singh1. "Endodontic implants.”Natl J Maxillofac Surg. 2014 Jan-Jun; 5(1): 70-73.

4. Berthold C, Auer FJ, Potapov S, Petschelt A. Rigidity evaluation of quartz-fiber splints compared with wirecomposite splints. Dent Traumatol. 2012 Feb;28(1):65-74.

5. M. J. Bharath,C.K. Sahadev,Peaveen Kumar M.R.,Swetha H. B., "Intraradicular splinting of a horizontally fractured upper central incisor - A case report". Endodontology 2015;23:95-99.

6. Sübay RK, Sübay MO, Yilmaz B, Kayataş M.Intraradicular splinting of a horizontally fractured central incisor: a case report. Dent Traumatol. 2008 Dec;24(6):680-4.

7. Chirag Macwan, Anshula Deshpande, "Mineral trioxide aggregate (MTA) in dentistry: A review of literature". 2014;6:71-74

8. Bhagwat SA, Hegde S, Mandke LP. An investigation into the effectiveness of periapical surgery with BiodentineTM used as a root-end lling alone or in combination with demineralized freeze-dried bone allograft and plasma rich brin: A 6 months follow-up of 17 cases. Endodontology 2016;28:11-7.

*Corresponding author:

Dr. Sumita Bhagwat, Professor, Dept of Conservative Dentistry \& Endodontics, DYPU School of Dentistry, Nerul, Navi Mumbai. Maharashtra.

Phone: +9109819876828

Email: sumita1572@gmail.com

Financial or other Competing Interests: None. 